\title{
Differential pricing: solidarity at times of financial crisis
}

\author{
Flaminia Macchia \\ From 7th European Conference on Rare Diseases and Orphan Products (ECRD 2014)
}

The financial crisis which has hit Europe (and beyond) in 2008 has been described as a "health system shock" by the WHO which has urged EU Member States to ensure that the national healthcare systems would continue to promote universal access to health services by increasing efficiency in the health sector.

The challenge for Member States is to ensure access to innovative medicines for unmet medical needs, while at the same time meeting cost containment objectives and rewarding innovation.

The need for improving sustainability of EU health systems has led to thorough analysis of different pricing models in Europe which showed substantial support of a wide range of stakeholders (including research-based industry, patients and payers) in favour of a differential pricing system as a reimbursement policy measure for new and cost-intensive medicinal products, which is the case for most orphan medicinal products (OMPs).

One way to reduce the impact of OMPs on national healthcare budgets is to differentiate prices according to different levels of Gross Domestic Products (GDPs) and introduce some sense of proportionality between a country's ability to pay and a fair level of reward for innovation.

The idea for this differential pricing system would therefore be to introduce a price differentiation not country by country but by "clusters of countries": High, Medium and Low income countries, knowing that in Europe the GDP per capita varies from 1 to 6, with Luxembourg being the highest and Bulgaria the lowest.

In a first phase, differential pricing would be limited to medicinal products responding to high unmet medical need: a price would be agreed on the basis of a valuebased pricing system, with the value being assessed with the EU Transparent Value Framework delivered by the MoCA (Mechanism of coordinated Access) process.

\footnotetext{
EURORDIS
} Attribution License (http://creativecommons.org/licenses/by/4.0), which permits unrestricted use, distribution, and reproduction in any medium, provided the original work is properly cited. The Creative Commons Public Domain Dedication waiver (http:// creativecommons.org/publicdomain/zero/1.0/) applies to the data made available in this article, unless otherwise stated. and take full advantage of:

- Convenient online submission

- Thorough peer review

- No space constraints or color figure charges

- Immediate publication on acceptance

- Inclusion in PubMed, CAS, Scopus and Google Scholar

- Research which is freely available for redistribution Submit your manuscript at
www.biomedcentral.com/submit C BioMed Central \\ () Biomed Central}

Then variations by cluster would apply within a range om minus to plus $10 \%$.

Two main obstacles to the introduction of a differenpricing system have been identified as being the Reference Pricing and the practice of parallel The reflection process is still on-going at EU level on differential pricing as a way to address the three following main policy objectives: timely and equitable access to tion. There is an overall need for political support from Member States and industry.

doi:10.1186/1750-1172-9-S1-O28

Cite this article as: Macchia: Differential pricing: solidarity at times of financial crisis. Orphanet Journal of Rare Diseases 2014 9(Suppl 1):O28. 